\title{
Establishing closure targets for discharge to temporary waters - a review
}

\author{
PL Whittle Hydrobiology, Australia \\ AM Leggett Hydrobiology, Australia
}

\begin{abstract}
Temporary waters include intermittent and ephemeral streams, lakes, pools and wetlands and are found throughout the world, largely in arid and semi-arid environments. The development of resource projects near temporary waters requires the determination of potential impacts pre, during and post mining which is often difficult to quantify and monitor due to the highly variable nature of the systems. In Australia, the current water quality guidelines for the protection of aquatic ecosystems are unsuitable for application in temporary waters and it is acknowledged that there is a need to develop guidance for these waters. A review of international practice finds a similar issue where current policies for protection and assessment and management guidelines generally are found to be lacking. A rigorous scientific approach for defining and monitoring temporary waters, which takes into account high levels of variability and is transferable across environments, is required. The authors outline key factors which need to be considered when developing site specific water quality targets for temporary waters and a potential approach which can be implemented in a range of environments.
\end{abstract}

\section{Introduction}

Temporary waters are water bodies which are characterised by periods of inundation and drought. These can be flowing or standing waters which are wetted on a cyclic basis, such as seasonal systems, or on a more episodic basis associated with infrequent high rainfall weather events. Temporary waters can include intermittent and ephemeral streams, lakes, pools and wetlands and are found throughout the world, largely in arid and semi-arid environments. Whilst a large proportion of the world's waterbodies are naturally temporary in nature, anthropogenic influences and impacts, such as water abstraction, impoundment and climate change has contributed to formerly perennial systems also becoming temporary (Buttle et al. 2012; Carlisle et al. 2011; Datry et al. 2014; Larned et al. 2010).

Historically, temporary stream studies were few and far between, especially when compared to studies involving perennial systems; however, the field has been growing in recent years (Larned et al. 2010; Leigh 2015). The recognition of the importance of temporary waters, especially in arid and semi-arid regions, as important habitats and links between water sources, is becoming more apparent. Even when a temporary water body is in a dry state, they support a diverse terrestrial habitat and the disconnected pools that persist during dry periods act as refuges for semi-aquatic and aquatic organisms (Datry 2012; Steward et al. 2012; Sheldon et al. 2010). Whilst research concerning temporary waters is increasing, management approaches have not been implemented at the same rate. Indeed, temporary waters may not even be recognised as a waterbody within legislation and, therefore, guidance on protecting and managing them has not been developed.

Impacts to temporary water bodies such as urbanisation, agriculture, livestock, water supply management and mining are all addressed to varying degrees in the available literature (Arthington \& Balcombe 2011; Buttle et al. 2012; Levick et al. 2008; Steward et al. 2012). In relation to mining impacts, Steward et al. (2012) highlight the vulnerability of temporary rivers because they are often used as drains to dispose of mine wastewater or stormwater. There is also the issue of altering the hydrology from one of natural 
intermittence to permanent flow (e.g. mine pit dewatering) and the closure implications for returning the system to an intermittent state (Reich et al. 2009).

This paper provides a brief review of the legal status and associated guidance concerning temporary waters providing a snapshot of the current state of protection for these systems in various jurisdictions. Approaches for classifying temporary waters are also reviewed, highlighting one of the main issues which needs to be addressed before temporary water assessment and management guidance can be developed and successfully implemented. The authors then discuss what they believe to be the most important principles and considerations to be taken into account when establishing water quality closure targets for temporary waters and the implications for mine closure planning.

\section{Overview of international guidance in relation to temporary waters}

Setting targets for post-mine closure water quality is usually done within the context of regulatory requirements/guidance and supporting legislation within the country of jurisdiction. While temporary waters are common in most regions of the world, surprisingly little guidance exists which is specific to their assessment and management (Prat et al. 2014). A lack of adequate management practices, objective monitoring procedures, protective policies and legislation leaves temporary waters susceptible to damage (Datry et al. 2014) as inappropriate management principles are applied. However, a review of ecological research and management of intermittent rivers by Leigh et al. (2015) finds that research is increasing and a policy shift is occurring to improve management and legislative protection status of these systems.

In the United States (US), a 2006 Supreme Court ruling brought attention to the jurisdictional status of temporary waters under the Clean Water Act, the chief legislation which protects waterways (Squillace 2006). The ruling found that a temporary stream or adjacent wetland must have a 'significant nexus' to 'navigable water' in the US for the former to fall under the jurisdiction of the Clean Water Act, thus protecting it from development and alteration. This effectively resulted in many non-navigable streams and adjacent wetlands not being considered jurisdictional without evidence of chemical, physical and/or biological interaction or influence on navigable waters (Leibowitz et al. 2008) and, according to Caruso (2011), significantly reduced the protection of intermittent and ephemeral streams and geographically isolated wetlands in the US. Currently, protection for these waters is determined on a case-by-case basis; however, a proposed ruling by the US Environmental Protection Agency (USEPA) will attempt to provide greater protection for most temporary waterways (Acuña et al. 2014). The legal recognition and protection of these systems will potentially pave the way for specific guidance on how to manage and assess them.

Neighbour to the US, Canada, appears to also be lacking in dedicated legislation or regulations dealing with temporary waters. Whilst Canada does have well developed and established water quality objectives and guidelines, no mention of their applicability to temporary waters is found within the literature. A review of temporary stream hydrology in Canada found a lack of data concerning these systems and no clear indication of even the proportion of drainage networks that consist of temporary streams (Buttle et al. 2012).

In the European Union (EU), the European Water Framework Directive (EWFD) provides an integrated river basin management approach aimed at setting objectives for water protection. Within this framework, the 'typology' of a temporary stream will determine whether it is recognised as a water body and the mechanism for defining the type can differ between river basins and jurisdictions (Acuña et al. 2014). This has resulted in inconsistent legal and protection status for these systems across the Union and in order to tackle this issue, the Mediterranean Intermittent River ManAGEment (MIRAGE) project was instigated with the aim to assess ecological status of intermittent streams and develop adaptive assessment methods suited to varying hydrological conditions (Leigh et al. 2015). In terms of temporary standing waters in the EU, Mediterranean Temporary Ponds and turloughs (Icelandic disappearing lakes) are defined as priority habitat according to the Natura 2000 network of the EU (Zacharias et al. 2007; Council Directive 92/43/EEC of 21 May 1992 on the Conservation of Natural Habitats and of Wild Flora and Fauna 1992) although 
guidance relating to managing these sites are not specific to their temporary nature (European Commission 2000).

The Australian context, where approximately two-thirds of the country is semi-arid to arid, provides a greater legislative recognition of temporary waters. Federal and state legal definitions, in many parts of Australia explicitly, include temporary streams and rivers as watercourses (Acuña et al. 2014). A National Water Quality Management Strategy and Water Quality Guidelines provide for the protection of the nation's water resources. The guidelines recognise the diverse range of ecosystem types in Australia, including static, flowing, ephemeral, fresh, brackish and saline and the inherent variability that can occur naturally through drought, flood or climatic events, however stops short at developing guidance for ephemeral rivers or saltwater lakes due to insufficient information to characterise water quality (ANZECC/ARMCANZ 2000). Currently, as part of the periodic revision of the guidelines, the provision of guidance specific to temporary waters is being developed with the aim of being used by industry, consultants and regulators to better manage these systems that are prevalent within the Australian landscape.

South Africa, a country which also has large arid and semi-arid regions, provides protection for its water resources under the National Water Act (RSA 1998), which specifically recognises intermittently flowing channels and wetlands which are only periodically covered with water. Although specific guidance relating to temporary waters management in the context of mining impacts was not found, a significant amount of research focusses on these temporary systems providing insight into methodologies appropriate to their assessment (Day 2010; Seaman et al. 2013; Ewart-Smith et al. 2012).

On a global scale and within a broader ecological research movement of synthesis and analysis of multiple datasets from multiple locations, the Intermittent River Biodiversity Analysis and Synthesis (IRBAS) project has been established with the aim of improving the understanding of the biodiversity patterns in temporary streams, educating the stakeholders and the public of their importance and providing guidelines for policy makers and resource managers to better restore, protect and manage them (Datry et al. 2014).

The legal status and existence of regulation or guidance for temporary waters within a given jurisdiction will have considerable bearing on the ecosystem and water quality management requirements in regards to a mining development or closure. Mines which have been able to discharge to water bodies previously considered to be of low value may find the changing international perspective on temporary waters adds additional considerations to mine closure planning.

\section{Approaches to classifying temporary waters}

As seen from the review above, one of the difficulties with providing guidance for temporary waters is in the definition and classification, whether from a legislative point of view, in the case of the US, or through differences in methods, as in the EU. The approach taken to classify temporary water bodies will have implications for the type of guidance and management actions required to protect them. It is often important to identify the occurrence and type of temporary stream in a given landscape, since water quality protection measures adopted by management agencies are often related to stream type (Hansen 2001). Whilst flow duration is often used as the primary descriptor of different stream types, flow duration is seldom measured or verified (Hansen 2001). Another approach for classification is to assign a typology based on characteristics or conceptual models of ecological processes which is the basis of the MIRAGE project in the EU.

Currently in Europe, under the EWFD, there are two systems of river classification based on hydro morphological, climatic and geological factors available (Munné \& Prat 2004). Only one of the systems includes taking into account the hydrological regime and classifications often do not apply to intermittent rivers (Logan \& Furse 2002). A comparison of classification methods for a river basin in Spain found a lack of data for basins consisting of temporal and ephemeral flow variability (Munné \& Prat 2004), implying the river systems in these basins had not previously been recognised and classified at all. 
The MIRAGE project was created as an aid to classifying these systems and provides extensive tools to classify and understand the target temporary system (Prat et al. 2014). MIRAGE recognises that ecosystem quality standards which were developed for permanent streams may not be applicable to temporary streams for all or part of the time and the resultant MIRAGE Toolbox provides guidance for intermittent stream assessment through:

- "the determination of the hydrological regime of the stream;

- the design of adequate schedules for biological and chemical sampling according to the aquatic state of the stream;

- the fulfilment of criteria for designing reference condition stations;

- the analysis of hydrological modifications of the stream regime (with the definition of the hydrological status); and

- the development of new methods to measure the ecological status (including structural and functional methods) and chemical status when the stream's hydrological conditions are far from those in permanent streams." (Prat et al. 2014).

The MIRAGE approach essentially develops site specific guidance based on assessment of the hydrological regime, the hydrological status, the aquatic state, and the ecological and chemical status of the system.

In Australia, a national level approach has been developed for classifying aquatic ecosystems and habitat types within an integrated regional and landscape setting to provide consistency across jurisdictions (Aquatic Ecosystems Task Group 2012). This approach is known as the Australian National Aquatic Ecosystem Classification Framework (ANAE) and is semi-hierarchical, and attribute and biogeophysical based. The initial broad scale classification is based on landform, climate, hydrology, topography and water influence whilst further fine scale classification focusses on identifying the aquatic system and defining the attributes of the water body. Temporary waters would be classified at the broader scale when determining hydrological influences but additional attributes assigned at the lower level of classification would separate out the many different types, e.g. riverine, lacustrine, saline or fresh. Attributes include, among others, the system type, water source, water regime, water chemistry and substrate type; which all have a bearing on the ecological processes which will be present in the temporary waterbody (Aquatic Ecosystems Task Group 2012). In terms of management, this framework could provide the basis for generating a conceptual model of a target waterbody which can then be used to inform monitoring design, indicator selection, and appropriate reference data or guidelines.

Interestingly, classification using the 'top down' approach of ANAE was found to provide different groupings of water bodies within the Australian Murray-Darling system compared to a 'bottom up' statistical approach (Brooks at al. 2014). In addition, this study found that an unmodified application of the default ANAE classification methods could lead to over-classification where groupings were too specific to facilitate management goals.

South Africa has also developed national guidance for the classification of wetlands and aquatic ecosystems which specifically includes temporary waters (Ollis et al. 2013). This system is similar to the Australian ANAE framework in that it is a semi-hierarchical system where broad scale classifications are refined as the user works through the system and incorporates further attributes. There are six levels of classification with the initial levels (1-3) focussing on the broad context in which the wetland sits (regional setting and landscape unit), the intermediate levels (4-5) refining the classification in terms of hydro-geomorphic attributes and the hydrological regime, and the final level (6) applying descriptors such as $\mathrm{pH}$ and salinity. Temporary waters are defined at level 5 when the hydrological regime of the target wetland or aquatic ecosystem is being considered.

A review of the existing literature brings the conclusion that classifying temporary water bodies is largely a 'fit for purpose' exercise with a continuum of typologies dependent upon the level of variance allowed within any one grouping. It is a relatively easy exercise to put temporary waters within broad groups 
(e.g. salt lakes, episodic streams, clay pans, floodplain wetlands etc.). However, for the purpose of developing water quality targets, these groupings are seldom likely to represent truly similar systems. This issue is of particular concern where referential targets are developed based on comparing impacted and non-impacted systems of the same classification or type. The key considerations in classification of temporary waters for the purposes of developing mine closure water quality targets are:

- Ensure that the attributes chosen for site grouping are directly relevant to the value(s) being protected.

- If using an established classification method (e.g. ANAE), ensure that default attribute definitions are applicable to the system under consideration (e.g. default salinity thresholds separating a 'brackish' and 'saline' system may not reflect the salt tolerance of the local biota).

- Ensure water regime attributes reflect water quality drivers. The water regime or hydrocycle is likely to be significantly more important for the classification of temporary waters than perennial waters. Using broad default attributes (e.g. 'seasonally inundated' or 'aseasonally inundated') may not capture key drivers of water quality differences between sites such as the period between flows, residence time and exposure to peak flood events.

- Consider statistical classification approaches (e.g. PCA or non-metric MDS) to define suitable reference sites where a suitable level of site physical, hydrologic and biological information exists.

\section{$4 \quad$ Establishing water quality closure targets for temporary waters}

There is a natural desire amongst regulators and industry (proponents) to develop broadly applicable, simple and practical guidance on setting water quality targets. While this process is problematic for perennial systems, it is almost impossible for temporary systems. Attempts to generate a hierarchical or decision tree type process often leads to a mire of typologies and/or simplifications which require ever more site specific investigations to test their validity (Brooks at al. 2014; Day at al. 2010; Prat at al. 2014). As described above, temporary waters by description vary from inundated to dry phases and include a continuous gradient of states between these phases. Similarly, water quality often varies depending on the hydrological state or phase of the water body or drainage channel under management. This is particularly true of systems which evapo-concentrate following cessation of flow or inflows such as many salt lakes or remnant pools in temporary streams. Under these circumstances it may not be applicable to use standard methods used to set water quality targets in permanent waters (e.g. ANZECC/ARMCANZ 2000, CCME 2007, Whittle \& Smith 2013). As an example, in a natural system that changes from fresh immediately following inundation to hypersaline at the end of the drying phase, setting a salinity target protective of the fresh phase ecology would not be protective of the salt phase ecology and vice versa. In addition, it is guaranteed that the fresh phase salinity target would be exceeded at some point in the drying phase. In such a case it may be applicable to establish a water quality target(s) for fresh phase (flood/flowing) ecology (e.g. larval and juvenile fish lower salinity tolerance) and a separate higher salinity target for drying phase refugia (e.g. adult fish higher salinity tolerance; Nielsen et al. 2003).

While the water (flow) regime types and biological/chemical/physical processes within temporary waters vary widely both between systems and even within a system, there are some general principals or considerations when establishing water quality targets:

- Set the temporal and spatial boundaries for your target value: if the management objective is to protect a particular ecological process (e.g. freshwater fish breeding and establishing metabolic reserves in preparation for estivation) then the water quality target value should be relevant only to the period of the hydrocycle and physical habitat in which that process occurs. The variability of temporary waters increases the likelihood that target values will be exceeded for at least part of the hydrocycle, potentially diverting management response and effort to 'false' or naturally occurring non-compliances. 
- Understand the water flow regime: related to the point above, having a rigorous conceptual model for the water regime (including the hydrograph and water budget) for the system under management is important for permanent waters but likely to be critical for temporary waters. Even for systems where seasonal flows are relatively predictable, flow/rainfall patterns antecedent to a monitoring event can be highly influential on the spot water quality at the time of sampling (Belnap et al. 2005; Datry 2012; Leigh et al. 2015). Understanding groundwater/ hyporheic inputs, particularly during recessional and drying phases, can be important for some systems. Permanent and semi-permanent pool refugia may still receive inflows from dry stream beds through hyporheic flow for a period following the cessation of surface flow in these streams (Larned et al. 2010). This water can be of significantly different quality to the meteoric water dominated surface flow phase (more saline, low dissolved oxygen, higher dissolved metals etc.). As an example, continuous conductivity loggers coupled with salt balance/major ion calculations can be used to define periods under which different water sources may become dominant.

- Understand the water quality regime: by knowing the relationship between water quality indicator values and specific phases of the hydrograph it is more likely to be possible to partition water quality targets between these phases. The process of obtaining sufficient data to establish a hydrograph phase/water quality relationship is made more complicated in temporary waters due to the reduced temporal opportunities to collect data. For example, if a peak flow period typically lasts for only one month per year (variable at that), a three year monthly baseline sampling program may only provide three data points for that hydrograph phase. The improving availability of relatively cheap continuous loggers for range of parameters (e.g. EC, turbidity, water level, temperature, dissolved oxygen etc.) is providing a valuable tool for understanding temporary waters.

- Understand the indicator/management value relationship: establishing a target value for a particular indicator (e.g. salinity, macroinvertebrate diversity etc.) should be undertaken with a clear understanding of the relationship between the management value being protected and a relevant range of indicator values. If the management value is simply to keep key water quality indicators within 'natural' statistical ranges (e.g. ANZECC/ARMCANZ 2000) then this goal should be explicitly stated in any associated management plan (e.g. the mine closure plan). Alternately, target values designed to be protective of management values (objectives) relating to specific ecological processes (e.g. the physiological response of a high conservation value aquatic species) may need to be stated within the context of the lines of evidence for the relationship between the two. For example, an assumption may be that a freshwater crayfish species can survive low dissolved oxygen (DO) bottom waters at night when they can walk up the bank to more oxygenated surface waters, but need a minimum (target value) DO value in bottom waters during daylight when they need to retreat to deeper water to avoid predation from birds. In this case, a day time (midday) DO target value for bottom waters during the recessional/drying flow period may be set but allow flexibility for low DO discharge at night.

An important consideration in setting water quality targets for recessional or drying phase waters is that dilution of contaminants is reduced and accumulation/evapo-concentration can occur (ANZECC/ARMCANZ 2000). This is particularly relevant where a discharge to the water body occurs on a perennial or dry season basis (e.g. mine dewatering) when dilution from natural flows is absent or significantly reduced (Smith et al. 2004; Gallaher 1983). Under these conditions, water quality in remnant pools, which can be important refuges for aquatic flora and fauna (Sheldon et al. 2010), can deteriorate quickly. In addition, storage of contaminants in dry river bed sediments, subsequent geochemical transformations (e.g. the Birch effect) and remobilisation during flushing events (Smith et al. 2004; Fisher et al. 1998; Larned 2010) can cause pulses of poor water quality during periodic flow events (DEHP 2009; Larned 2010; Leigh et al. 2015). The dry phase biogeochemistry within sediments and the hyporheic zone of dry stream beds is further complicated by the biogeochemistry occurring in pool refugia which can itself be causing stress on the resident biota through anoxia, nutrient release and subsequent algal blooms (von Schiller et al. 2011). 
Where a refugia may exceed a water quality 'tipping point' due to cumulative stressors (natural and anthropogenic), end-of-pipe water quality targets may not be protective and therefore ambient receiving environment targets should be used. Allowance for a mixing zone of lower quality water may also be appropriate (ANZECC/ARMCANZ 2000).

Setting of water quality targets for mine closure is typically considered in relation to background (baseline) and/or reference site condition (e.g. DEHP 2009, ANZECC/ARMCANZ 2000). Characterising baseline conditions and finding suitable reference sites can be more complicated with temporary water systems due to the inherent variability and gradients in characterising parameters. Finding reference sites with similar size catchments and in similar geographical context to the potential impact site(s) is more critical than with perennially flowing systems. The use of assessment methods developed for perennial waters to determine the ecological health of temporary systems can be appropriate, particularly if the temporary systems are relatively predictable (Mazor et al. 2014). However, temporary systems are more likely to be appropriately assessed using methods tailored for site specific ecological and hydrologic conditions (Morais et al. 2004; Leigh et al. 2015).

As indicated above, the temporal applicability of any water quality target(s) is likely to be a more important consideration in temporary waters. Some jurisdictions have taken the view that poor water quality during 'first flush' events may not be a significant issue in temporary waters as the dry phase ecology will be resilient to these initial impacts (DEHP 2009). However, if permanent or semi-permanent pool refugia are present then the opposite may be true, with first flush events occurring at the end of the dry when these pools are at their most stressed. The use of annualised statistical parameters as a water quality target (e.g. a percentile of the baseline range) is common place in perennial systems, though is skewed towards being too broad in the context of highly variable temporary water systems. Setting targets for defined hydrological phases (e.g. first flush, peak flow, recessional flow, drying and dry (pool refugia)) may need to be considered.

Even with regard to flowing or permanent waters, it is acknowledged that there is significant uncertainty associated with the process of deriving and applying water quality guidelines and they should not be used as mandatory standards. Lack of species-specific biological effects data, uncertainty of contaminant behaviour under field conditions and uncertainties related to water quality measurement techniques contribute to a cautious approach when developing and applying water quality guidelines (ANZECC/ARMCANZ 2000).

\section{$5 \quad$ Implications for mine closure planning}

Post-closure management of the hydrological regime (surface and groundwater) is often the major risk and, therefore, a major consideration in mine closure planning. With the increasing requirement for long-term or even perpetual management of mine sites post-closure (DMP/EPA 2011), low or no-maintenance water engineering solutions are essential to successful close-out of mining operations. Water retention and management infrastructure used during mine operations (e.g. sedimentation dams, water supply dams, treatment plants etc.) are likely to need decommissioning to facilitate a return to a more natural water regime post-closure. Unregulated or minimally regulated water discharge from the mine site post-closure requires that consideration is given to not just the water quality and quantity, but also the temporal pattern of discharge where flows in the receiving environment are naturally ephemeral or episodic. Increased hydraulic conductivity and storage within waste rock (overburden) dumps, perched water in tailings dams, depressurisation structures (e.g. adits/drains) and intercepting infrastructure (voids/bunds etc.) can all alter the temporal nature of water discharge by changing water release dynamics. This in turn allows drainage to occur from the site for a period after natural flows may have ceased in the receiving environment.

The setting of water quality targets to provide an indication of management objectives and system performance post-closure is considered best practice (ANZMEC/MCA 2000; DMP/EPA 2011). In the case of discharge to temporary waters, there is little regulator guidance though this has been attempted 
(DEHP 2009; Outback Ecology 2009). For mines operating in highly ephemeral systems there may be discharge of poor quality water into non-flowing streams or dry water bodies where accumulation and biogeochemical transformation of contaminants may occur. Subsequent mobilisation of contaminants (including sediments) upon significant flow events can impact downstream ecological refugia. Mine closure planning should consider that even discharge to dry creek beds can produce deterioration in downstream water quality long after discharge has discontinued, often in pulses which may not be measured by sporadic monitoring (Leigh et al. 2015). An appropriate monitoring site may be well off the mine lease at a downstream permanent pool or other recipient of flushing flows (e.g. a wetland basin, off-river floodplain water body or internally draining lake). Where the entire receiving drainage course becomes dry on a regular basis it is likely that the ecology will be somewhat resistant to poor water quality in the early stages of the wetting cycle (first flush). However, it may become more vulnerable to perturbation in the weeks following as the drought resilient phases of the resident biota (e.g. encysting and diapausing invertebrates, estivating vertebrates and hyporheic infauna) break to start wet season ecological phases (Datry et al. 2014).

Water quality targets for temporary systems post-closure should be set with a clear understanding of the temporal and spatial variability of the receiving water body, including the relationship between stages within the flow regime, water quality and aquatic ecological dependencies. It is likely that a temporary water system will require water quality targets that are clearly defined for separate stages in the flow regime and potentially ecological phases where the flow regime is highly episodic and unpredictable.

\section{References}

Acuña, V, Datry, T, Marshall, J, Barceló, D, Dahm, CN, Ginebreda, A, McGregor, G, Sabater, S, Tockner, K \& Palmer, MA 2014, 'Why Should We Care About Temporary Waterways?', Science, vol. 343, pp. 1080-1081.

ANZECC/ARMCANZ (Australian and New Zealand Environment and Conservation Council \& Agriculture and Resource Management Council of Australia and New Zealand) 2000, Australian and New Zealand Guidelines for Fresh and Marine Water Quality: Volume 1, The Guidelines, ANZECC \& ARMCANZ, Canberra.

ANZMEC/MCA (Australian and New Zealand Minerals and Energy Council \& Minerals Council of Australia) 2000, Strategic Framework for Mine Closure, ANZMEC \& MCA, National Library of Australian Catalogue Data.

Aquatic Ecosystems Task Group 2012, Aquatic Ecosystems Toolkit Module 2: Interim Australian National Aquatic Ecosystem Classification Framework Version 1.0, Department of Sustainability, Environment, Water, Population and Communities, Commonwealth of Australia.

Arthington, AH \& Balcombe, SR 2011, 'Extreme flow variability and the 'boom and bust' ecology of fish in arid-zone floodplain rivers: a case history with implications for environmental flows, conservation and management', Ecohydrology, vol. 4, pp. 708-720.

Belnap, J, Welter, JR, Grimm, NB, Barger, N \& Ludwig, JA 2005, 'Linkages between Microbial and Hydrologic Processes in Arid and Semiarid Watersheds', Ecology, vol. 86, pp. 298-307.

Brooks, S, Cottingham, P, Butcher, R and Hale, J 2014, Murray-Darling Basin aquatic ecosystem classification: Stage 2 report, Peter Cottingham \& Associates report to the Commonwealth Environmental Water Office and Murray-Darling Basin Authority, Canberra.

Buttle, JM, Boon, S, Peters, DL, Spence, C, (Ilja) van Meerveld, HJ \& Whitfield, PH 2012, 'An Overview of Temporary Stream Hydrology in Canada', Canadian Water Resources Journal, vol. 37, pp. 279-310.

Carlisle, DM, Wolock, DM \& Meador, MR 2011, 'Alteration of Streamflow Magnitudes and Potential Ecological Consequences: A Multiregional Assessment', Frontiers in Ecology and the Environment, vol. 9, pp. 264-270.

Caruso, BS 2011, 'Science and Policy Integration Issues for Stream and Wetland Jurisdictional Determinations in a Semi-Arid Region of the Western U.S', Wetlands Ecology and Management, vol. 19, pp. 351-371.

CCME (Canadian Council of Ministers of the Environment) 2007, A Protocol for the Derivation of Water Quality Guidelines for the Protection of Aquatic Life 2007 Canadian Environmental Quality Guidelines, Canadian Council of Ministers of the Environment, Winnipeg.

Council Directive 92/43/EEC of 21 May 1992 on the Conservation of Natural Habitats and of Wild Flora and Fauna 1992, Official Journal of the European Communities 35 (July).

Datry, T 2012, 'Benthic and Hyporheic Invertebrate Assemblages along a Flow Intermittence Gradient: Effects of Duration of Dry Events: River Drying and Temporary River Invertebrates', Freshwater Biology, vol. 57, no. 3, pp. 563-574.

Datry, T, Larned, ST \& Tockner, K 2014, 'Intermittent Rivers: A Challenge for Freshwater Ecology', BioScience, vol. 64, no. 3, pp. $229-235$.

Day, J, Day, E, Ross-Gillespie, V, \& Ketley, A 2010, The Assessment of Temporary Wetlands during Dry Conditions: Report to the Water Research Commission, Water Resource Commission, Gezina, South Africa.

DEHP (Department of Environment and Heritage Protection) 2009, Monitoring and Sampling Manual 2009 Version 2 July 2013, DEHP, Government of Queensland, Australia. 
DMP/EPA (Department of Mines and Petroleum \& Environmental Protection Authority) 2011, Guidelines for Preparing Mine Closure Plans, DMP \& EPA, Government of Western Australia, June 2011.

European Commission 2000, Managing Natura 2000 Sites: The Provisions of Article 6 of the "Habitats" Directive 92/43/EEC, European Commission \& Office for Official Publications of the European Communities (eds), Luxembourg.

Ewart-Smith, JL, King, JM 2012, The Relationship between Periphyton, Flow and Nutrient Status in South-Western Cape Foothill Rivers and the Implications for Management: Report to the Water Research Commission, Gezina [South Africa]: Water Research Commission.

Fisher, SG, Grimm, NB, Martí, E, Holmes, RM \& Jones Jr, JB 1998, 'Material Spiralling in Stream Corridors: A Telescoping Ecosystem Model', Ecosystems, vol. 1, no. 1, pp. 19-34.

Gallaher, B 1983, 'The Puerco River: muddy issue raised by a mine dominated ephemeral stream', Water Quality in New Mexico, Proceedings of the 28th Annual New Mexico Water Conference, WRRI Report No. 169, pp. 60-68.

Hansen, WF 2001, 'Identifying Stream Types and Management Implications', Forest Ecology and Management, vol. 143, no. 1, pp. 39-46.

Larned, ST, Datry, T, Arscott, DB \& Tockner, K 2010, 'Emerging Concepts in Temporary-River Ecology', Freshwater Biology, vol. 55, no. 4, pp. 717-738.

Leibowitz, SG, Wigington, PJ, Rains, MC \& Downing, DM 2008, 'Non-Navigable Streams and Adjacent Wetlands: Addressing Science Needs Following the Supreme Court's Rapanos Decision', Frontiers in Ecology and the Environment, vol. 6, no. 7, pp. $364-371$.

Leigh, C, Boulton, AJ, Courtwright, JL, Fritz, K, May, CL, Walker, RH \& Datry, T 2015, 'Ecological Research and Management of Intermittent Rivers: An Historical Review and Future Directions', Freshwater Biology, July.

Levick, LR, Goodrich, DC, Hernandez, M, Fonseca, J, County, P, Semmens, DJ, Stromberg, J, Tluczek, M, Leidy, RA \& Scianni, M 2008, 'The Ecological and Hydrological Significance of Ephemeral and Intermittent Streams in the Arid and Semi-Arid American Southwest', Policy, vol. 50.

Logan, P \& Furse, M 2002, 'Preparing for the European Water Framework Directive? Making the Links between Habitat and Aquatic Biota', Aquatic Conservation: Marine and Freshwater Ecosystems, vol. 12, no. 4, pp. 425-437.

Mazor, RD, Stein ED, Ode, PR \& Schiff, K 2014, 'Integrating Intermittent Streams into Watershed Assessments: Applicability of an Index of Biotic Integrity', Freshwater Science, vol. 33, no. 2, pp. 459-474.

Morais, M, Pinto, P, Guilherme, P, Rosado, J \& Antunes, I 2004, 'Assessment of temporary streams: the robustness of metric and multimetric indices under different hydrological conditions', Hydrobiologia, vol. 516, pp. 229-249.

Munné, A \& Prat, M 2004, 'Defining River Types in a Mediterranean Area: A Methodology for the Implementation of the EU Water Framework Directive', Environmental Management, vol. 34, no. 5, pp. 711-729.

Nielsen, DL, Brock, MA, Rees, GN \& Baldwin, DS 2003, 'Effects of increasing salinity on freshwater ecosystems in Australia', Australian Journal of Botany 51, pp. 655-665.

Ollis, D, Snaddon, K, Job, N \& Mbona, N 2013, Classification System for Wetlands and Other Aquatic Ecosystems in South Africa: User Manual: Inland Systems.

Outback Ecology 2009, Development of Framework for Assessing the Cumulative Impacts of Dewatering Discharge to Salt Lakes in the Goldfields of Western Australia, Report for the Department of Water, Government of Western Australia, June 2009.

Prat, N, Gallart, F, Von Schiller, D, Polesello, S, García-Roger, EM, Latron, J, Rieradevall, M, Llorens, P, Barbera, GG, Britto, D, De Girolamo, AM, Dieter, D, Lo Porto, A, Buffagni, A, Erba, S, Nikolaidis, NP, Querner, EP, Tournoud, MG, Tzoraki, O, Skoulikidis, N, Gomez, R, Sanchez-Montoya, MM, Tockner, K \& Froebrich, J 2014, 'The Mirage Toolbox: An Integrated Assessment Tool For Temporary Streams: Mirage Toolbox', River Research and Applications, vol. 30, no. 10, pp. 1318-1334.

Reich, P, McMaster, D, Bond, N, Metzeling, L \& Lake, SP 2009, 'Examining the Ecological Consequences of Restoring Flow Intermittency to Artificially Perennial Lowland Streams: Patterns and Predictions from the Broken-Boosey Creek System in Northern Victoria, Australia', River Research and Applications.

RSA (Republic of South Africa) 1998, National Water Act 1998, Act no. 36, RSA.

Seaman, MT, Watson, M, Avenant, MF, Joubert, AR, King, JM, Barker, CH, Esterhuyse, S, Graham, D, Kemp, ME, le Roux, PA, Prucha, B, Redelinghuys, N, Rossouw, L, Rowntree, K, Sokolic, F, Van Rensburg, L, van der Waal, B, van Tol, J \& Vos, AT 2013, The Mokolo River Case Study, Water Resource Commision, South Africa.

Sheldon, F, Bunn, SE, Hughes, JM, Arthington, AH, Balcombe, SR \& Fellows, CS 2010, 'Ecological Roles and Threats to Aquatic Refugia in Arid Landscapes: Dryland River Waterholes', Marine and Freshwater Research, vol. 61, no. 8, pp. 885-895.

Smith, R, Jeffree, R, John, J \& Clayton, P 2004, Review of Methods for Water Quality Assessment of Temporary Stream and Lake Systems, Australian Centre for Mining Environmental Research.

Squillace, M 2006, 'From Navigable Waters to Constitutional Waters: The Future of Federal Wetlands Regulation', University of Michigan Journal of Law Reform, vol. 40, p. 799.

Steward, AL, von Schiller, D, Tockner, K, Marshall, JC \& Bunn, SE 2012, 'When the River Runs Dry: Human and Ecological Values of Dry Riverbeds', Frontiers in Ecology and the Environment, vol. 10 (4), pp. 202-209.

von Schiller, D, Acuña, V, Graeber, D, Martí, E, Ribot, M, Sabater, S, Timoner, X \& Tockner, K 2011, 'Contraction, fragmentation and expansion dynamics determine nutrient availability in a Mediterranean forest stream', Aquatic Sciences, vol. 73, pp. $485-497$.

Whittle, P \& Smith, REW 2013, 'Development and application of water quality criteria for reliable management of off-site risk', International Mine Water Association Annual Conference 2013, Colorado, USA.

Zacharias, I, Dimitriou, E, Dekker, A \& Dorsman, E 2007, 'Overview of Temporary Ponds in the Mediterranean Region: Threats, Management and Conservation Issues', Journal of Environmental Biology, vol. 28, no. 1, pp. 1-9. 
